Bull. Mater. Sci., Vol. 36, No. 6, November 2013, pp. 1057-1066. (C) Indian Academy of Sciences.

\title{
Effect of TiN particulate reinforcement on corrosive behaviour of aluminium 6061 composites in chloride medium
}

\author{
H C ANANDA MURTHY*, V BHEEMA RAJU ${ }^{\dagger}$ and C SHIVAKUMARA \\ Department of Chemistry, R N Shetty Institute of Technology, Rajarajeshwari Nagar, Bangalore 560 098, India \\ $\dagger^{\dagger}$ Department of Chemistry, Dr. Ambedkar Institute of Technology, Bangalore 560 056, India \\ $¥$ Solid State and Structural Chemistry Unit, Indian Institute of Science, Bangalore 560 012, India
}

MS received 12 April 2012; revised 20 July 2012

\begin{abstract}
In the present investigation, the corrosive behaviour of Al 6061-TiN particulate composites prepared by liquid metallurgy has been studied in chloride medium using electroanalytical techniques such as Tafel, cyclic polarization and electrochemical impedance spectroscopy (EIS). Surface morphology of the sample electrodes was examined using scanning electron micrography and energy dispersive X-ray methods. X-ray diffraction technique was used to confirm inclusion of TiN particulates in the matrix alloy and identify the alloying elements and intermetallic compounds in the Al 6061 composites. Polarization studies indicate an increase in the corrosion resistance in composites compared to the matrix alloy. EIS study reveals that the polarization resistance $\left(R_{p}\right)$ increases with increase in TiN content in composites, thus confirming improved corrosion resistance in composites. The observed decrease in corrosion rate in the case of composites is due to decoupling between TiN particles and Al 6061 alloy. It is understood that after the initiation of corrosion, interfacial corrosion products may have decoupled the conducting ceramic TiN from Al 6061 matrix alloy thus eliminating the galvanic effect between them.
\end{abstract}

Keywords. Composites; corrosion; SEM; EDX; EIS

\section{Introduction}

Particulate-reinforced aluminium metal matrix composites (Al MMCs) and other aluminium-based materials having a wide range of applications in diverse fields such as light weight automotive structures, forgings for suspension, chassis, as well as advanced automotive components are exposed to a wide variety of corroding environments. Alloys of Al reinforced with ceramic oxides, carbides, nitrides and mineral silicate particulates possess attractive characteristics such as high specific modulus, high specific strength, low thermal expansion coefficient, light weight and low cost (Berghezan 1966; Kelly 1967; Chawla and Chawla 2006) and superior corrosion resistance.

Studies on aluminium alloys reinforced with $\mathrm{SiC}$ (Clyne and Withers 2001), B (Agarwal and Broutman 1980), $\mathrm{Al}_{2} \mathrm{O}_{3}$ (Chawla and Chen 2001), TiC (Kainer 2006) and $\mathrm{ZrB}_{2}$ (Froyen and Verlinden 1994) report lower corrosion resistance for the composites compared to matrix alloys, owing to galvanic corrosion. On the other hand, $\mathrm{Al}$ composites reinforced with garnet (Trumper 1987), albite (Johansen 2010), quartz (Nair et al 1985) and glass fibre (Pohlman 1978) exhibited higher corrosion resistance compared to their matrix alloys. Recent studies on the corrosion resistance of $\mathrm{TiB}_{2}$ particulate-reinforced A356 alloy show a marked

\footnotetext{
*Author for correspondence (anandkps7@yahoo.com)
}

decrease with increase in $\mathrm{TiB}_{2}$ content as reported by Sun et al (Paciej and Agarwala 1986). In the case of TiC-Al 2024 composites, the $\mathrm{TiC}$ reinforcement is reported to decrease the anodic current density as well as amount and size of the pit (Trowsdale et al 1996). AlN particles which are highly insulating are reported to increase the susceptibility to pitting attack attributable to microgalvanic coupling between the matrix and reinforcement and hydrolysis of AlN particles (Pfeifer 1977). The corrosion resistance of Al-Mg and $\mathrm{Al}-\mathrm{Cu}$ composites is found to be higher than that of composites reinforced with mica particles (Trzaskoma et al 1983). The conflicting results can possibly be explained by differences in fabrication methods and composition which yield dramatically different electrochemical behaviours (Griffiths and Turnbull 1994).

The observed variation of corrosion resistance in Al MMCs is attributed to chemical or mechanical factors such as composition of the matrix alloy, nature of reinforcing particles, fabrication methods, chemical or mechanical factors such as alloying, segregation, interfacial reactions, oxidized layers, residual stress around reinforced particles in the matrix and galvanic coupling between matrix and reinforcement.

The corrosive behaviour of reinforced $\mathrm{Al}$ composites investigated in acidic, neutral, alkaline and various salt media reveal that $\mathrm{Al}$ composites suffer greater localized pitting corrosion in chloride ion environment compared to other media. Thus since Al MMCs lose their mechanical properties due to corrosion and lead to failure during service, research on 
the corrosive behaviour is equally important as studies on fabrication and mechanical behaviour of Al MMCs.

The present investigation involves the study of corrosive behaviour of unreinforced Al-6061 matrix and its TiN particulate composites in $\mathrm{NaCl}$ medium. Titanium nitride is a hard, dense and refractory material with low electrical resistivity $\left(\sim 10^{-7} \mathrm{ohm} \mathrm{cm}\right)$ and is isomorphous with $\mathrm{TiC}$. TiN is a good reinforcement for aluminium matrix, as it is known to enhance corrosion resistance of the matrix. The main objective of the present study is to establish the role and effectiveness of $\mathrm{TiN}$ on the corrosive behaviour of $\mathrm{Al} 6061$ composites.

\section{Experimental: Material selection}

\subsection{Aluminium alloy 6061 matrix}

Aluminium alloy 6061 had the composition: $\mathrm{Si}-0.6 \%$, $\mathrm{Fe}-0.1 \%, \mathrm{Cu}-0.3 \%, \mathrm{Mn}-0.02 \%, \mathrm{Mg}-0.8 \%, \mathrm{Zn}, \mathrm{Cr}$, $\mathrm{Ti}-0.01 \%$ each and remaining $\mathrm{Al}$.

\subsection{Reinforcement}

TiC of A.R. grade was obtained from Sigma Aldrich and used as reinforcement in the form of particulates.

\subsection{Composite preparation}

The liquid metallurgy route using vortex technique was employed to prepare the composites. Addition of reinforcement material $\mathrm{TiO}_{2}$ into the molten Al-6061 alloy melt was carried out by creating a vortex in the melt using a mechanical stainless steel stirrer coated with alumina (to prevent migration of ferrous ions from the stirrer material to the alloy). The stirrer was rotated at a speed of $450 \mathrm{rpm}$ in order to create the necessary vortex. $\mathrm{TiO}_{2}$ particles were pre-heated to $400{ }^{\circ} \mathrm{C}$ and added into the vortex of liquid melt at a rate of $120 \mathrm{~g} / \mathrm{min}$. $\mathrm{TiO}_{2}$ particulates were in the size range of $50-80 \mu \mathrm{m}$. The weight percentage of $\mathrm{TiO}_{2}$ used was 2-6 in steps of $2 \%$. The composite melt was thoroughly stirred and subsequently degasifiers were added. Castings were produced in permanent moulds in the form of cylindrical rods (diameter, $30 \mathrm{~mm}$ and length, $150 \mathrm{~mm}$ ).

\subsection{Specimen preparation}

Cast material was cut into $20 \times 20 \mathrm{~mm}$ cylindrical pieces using an abrasive cutting wheel. The matrix alloy was also cast under identical conditions as composites, for comparison. The samples were successively ground using 240, 320, 400, 600, 800, 1000, 1500 and 2000 grade emery papers and polished according to standard metallographic techniques and degreased in acetone and dried. The samples were weighed up to fourth decimal place using electronic balance and the exact specimen dimensions were noted down. For polarization studies, composites and pure alloy matrix were cut into rectangular specimens of $2 \mathrm{~cm}$ length, $1 \mathrm{~cm}$ width and $1 \mathrm{~mm}$ thickness and prepared as described above.

\section{Results and discussion}

\subsection{Polarization measurements}

Titanium nitride is a hard, dense and refractory material with low electrical resistivity $\left(\sim 10^{-7} \mathrm{ohm} \mathrm{cm}\right)$ and is isomorphous with TiC. Also, TiN particles have poor wettability with liquid aluminium. The open circuit potentials (OCP) were recorded for Al6061 matrix alloy and its TiNcomposites $(2,4$ and $6 \mathrm{wt} \%)$ in three different concentrations of neutral $\mathrm{NaCl}$ media, viz. $0.1 \mathrm{~N}, 0.5 \mathrm{~N}$ and $1.0 \mathrm{~N}$ solutions. The plots for the matrix alloy and the composites in decinormal $\mathrm{NaCl}$ medium is shown in figure 1 and the evaluated open circuit potentials are given in table 1 . It is observed that the OCP values increase in positive direction with increase in $\mathrm{TiN}$ content, from $-0.8062 \mathrm{~V}$ for $\mathrm{Al} 6061$ matrix to $-0.7487 \mathrm{~V}$ for reinforced composites $(6 \mathrm{wt} \% \mathrm{TiN})$ in $0.1 \mathrm{~N}$ $\mathrm{NaCl}$ medium. Similar increase in OCP values in the positive direction with increase in TiN content is observed in $1 \mathrm{~N} \mathrm{NaCl}$ medium, from $-0.8987 \mathrm{~V}$ for Al 6061 matrix to $-0.7761 \mathrm{~V}$ for reinforced composites ( $\mathrm{TiN}-6 \mathrm{wt} \%$ ).

OCP values shift considerably towards negative direction for Al 6061 matrix alloy and its TiN composites, as shown in figures 2 and 3. The increase in OCP value in the cathodic direction is about $90 \mathrm{mV}$ as the concentration of $\mathrm{NaCl}$ is increased by one order of magnitude, for the matrix alloy as well as the composites. However, this increase in OCP value of $90 \mathrm{mV}$ for TiN reinforcement is lower when compared to the corresponding increase of $140 \mathrm{mV}$ for $\mathrm{Al}-\mathrm{TiO}_{2}$ composites.

Typical polarization curves for Al 6061 matrix alloy and composites containing 2, 4 and $6 \%$ by weight of TiN particulates in different concentrations of $\mathrm{NaCl}$ are shown in figures 4-6. The evaluated electrochemical corrosion parameters for the matrix alloy and the composites are

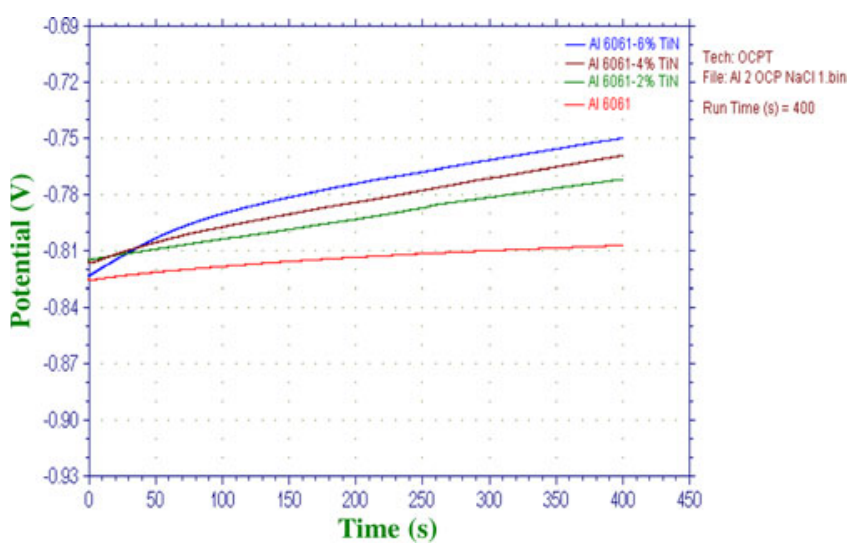

Figure 1. Open circuit potentials for A1 6061 matrix alloy and its TiN (2, 4 and $6 \mathrm{wt} \%$ ) composites in $0.1 \mathrm{~N} \mathrm{NaCl}$ medium. 
Table 1. Open circuit potentials of Al 6061 matrix alloy and its TiN composites in various concentrations of $\mathrm{NaCl}$ media.

\begin{tabular}{llcc}
\hline \multirow{2}{*}{$\begin{array}{l}\text { TiN content } \\
\text { in composites }\end{array}$} & \multicolumn{2}{c}{ OCP $\left(E_{\text {corr }}\right)$ values (in volts) in various NaCl media } \\
\cline { 2 - 4 } & $0.1 \mathrm{~N}$ & $0.5 \mathrm{~N}$ & $1.0 \mathrm{~N}$ \\
\hline $0 \%$ & -0.8062 & -0.8594 & -0.8987 \\
$2 \%$ & -0.7678 & -0.8398 & -0.8531 \\
$4 \%$ & -0.7562 & -0.7568 & -0.8007 \\
$6 \%$ & -0.7487 & -0.7503 & -0.7761 \\
\hline
\end{tabular}

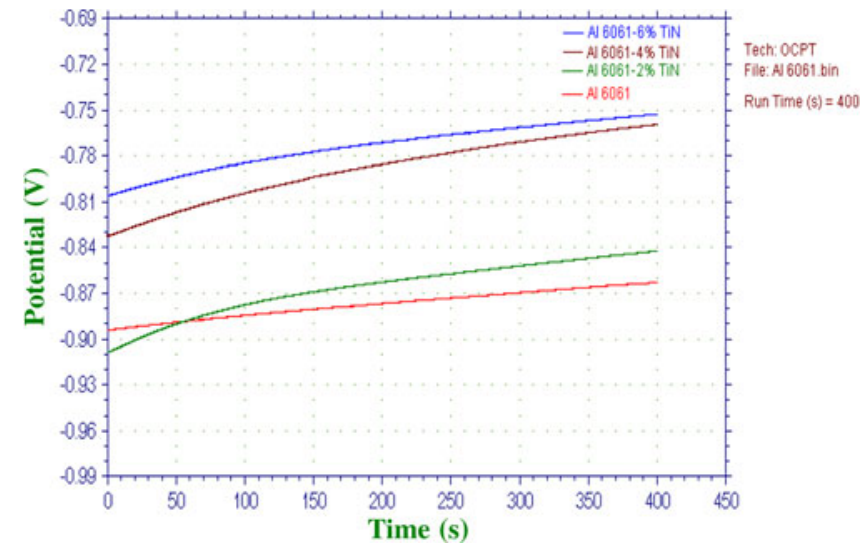

Figure 2. Open circuit potentials for $\mathrm{Al} 6061$ matrix alloy and its TiN (2, 4 and $6 \mathrm{wt} \%$ ) composites in $0.5 \mathrm{NaCl}$ medium.

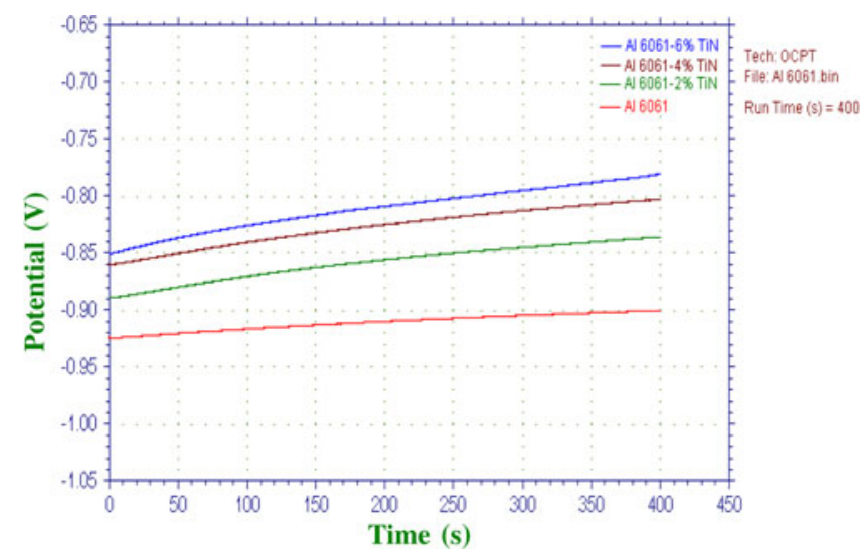

Figure 3. Open circuit potentials for $\mathrm{Al} 6061$ matrix alloy and its TiN (2, 4 and $6 \mathrm{wt} \%)$ composites in $1.0 \mathrm{NaCl}$ medium.

given in tables 2 and 3 . The corrosion parameters, corrosion current density $\left(I_{\text {corr }}\right)$ and corrosion rate were obtained from the Tafel polarization measurements. It can be observed from the Tafel plots and the tables that corrosion current values and corrosion rates decrease with increase in TiN content in the composites, in each of the $\mathrm{NaCl}$ concentrations. Cyclic polarization curves for $\mathrm{Al} 6061$ matrix alloy and composites containing 2, 4 and $6 \%$ by weight of TiN particulates, in $0.5 \mathrm{~N} \mathrm{NaCl}$ solution are shown in figure 7. Cyclic polarization curves of the reinforced and unreinforced $\mathrm{Al}$ alloys

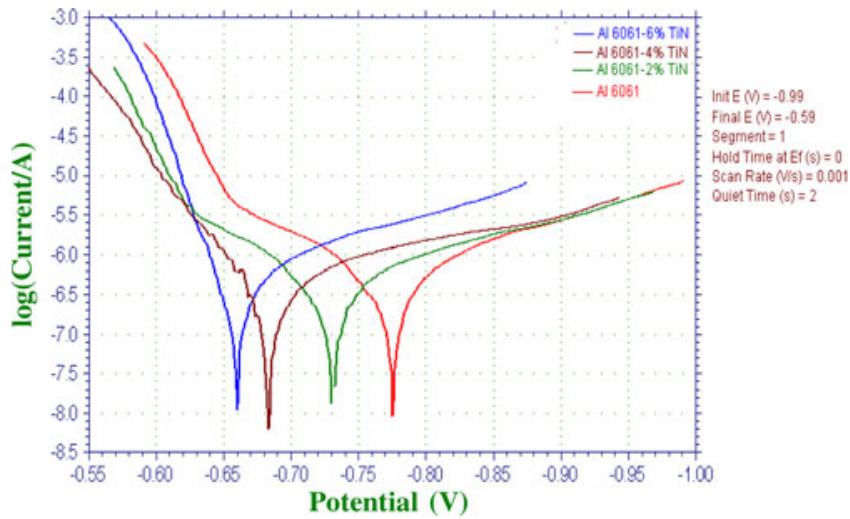

Figure 4. Tafel polarization plots for $\mathrm{Al} 6061$ matrix alloy and its TiN (2, 4 and $6 \mathrm{wt} \%)$ composites in $0 \cdot 1 \mathrm{NaCl}$ medium.

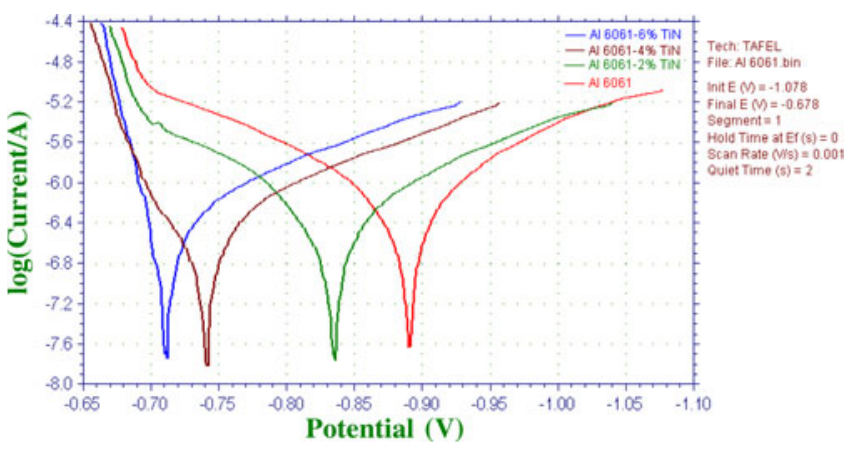

Figure 5. Tafel polarization plots for $\mathrm{Al} 6061$ matrix alloy and its TiN (2, 4 and $6 \mathrm{wt} \%$ ) composites in $0.5 \mathrm{NaCl}$ medium.

were found to be similar in overall shape. Cyclic polarization measurements show that the pitting potential increases towards positive direction with increase in TiN content confirming the results from other measurements that composites of TiN are more corrosion resistant than the matrix alloy.

Open circuit potential measurements revealed that the corrosion susceptibility of the matrix alloy decreases with increase in TiN content in the composites. TiN reinforcement particles thus impart good corrosion resistance to the Al-TiN composites with an increase in the concentration of the chloride medium from $0.1 \mathrm{~N}$ to $0.5 \mathrm{~N}$ to $1.0 \mathrm{~N} \mathrm{NaCl}$. Our results suggest the presence of lower percentage of TiN particulates 


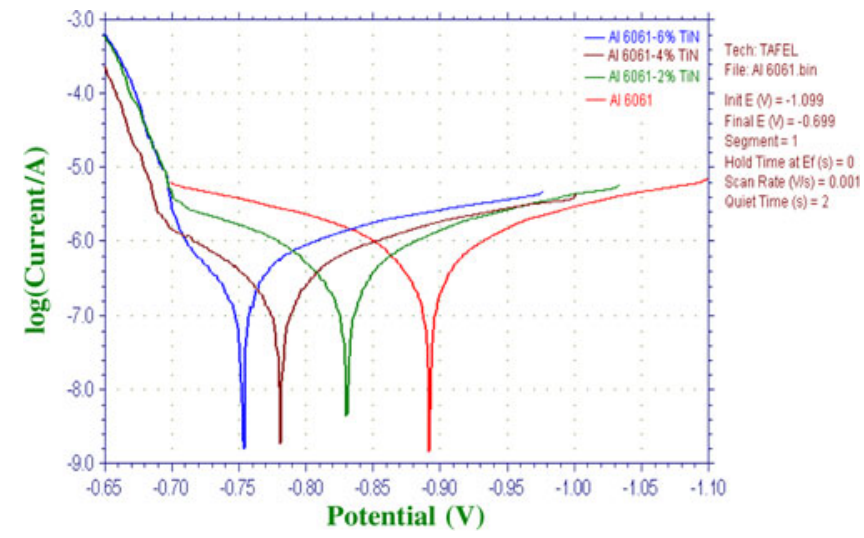

Figure 6. Tafel polarization plots for $\mathrm{Al} 6061$ matrix alloy and its TiN (2, 4 and $6 \mathrm{wt} \%$ ) composites in $1.0 \mathrm{NaCl}$ medium.

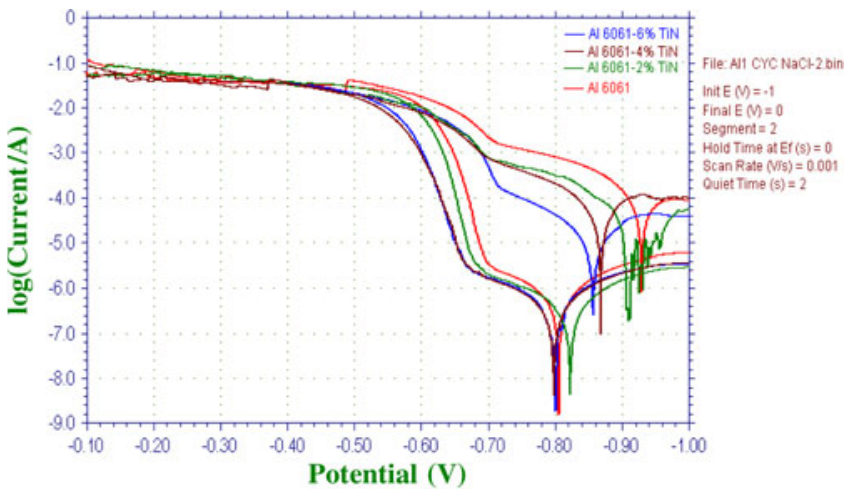

Figure 7. Cyclic polarization plots for $\mathrm{Al} 6061$ matrix alloy and its $\mathrm{TiN}(2,4$ and $6 \mathrm{wt} \%$ ) composites in $1.0 \mathrm{NaCl}$ medium.

Table 2. Corrosion current densities ( $\left.I_{\text {corr }}\right)$ of $\mathrm{Al} 6061$ matrix alloy and its $\mathrm{TiN}$ composites in various concentrations of $\mathrm{NaCl}$ media.

\begin{tabular}{llcr}
\hline \multirow{2}{*}{$\begin{array}{l}\text { TiN content } \\
\text { in composites }\end{array}$} & \multicolumn{3}{c}{ Corrosion current density, $I_{\text {corr }}\left(\mathrm{Acm}^{-2}\right)$} \\
\cline { 2 - 4 } $0 \%$ & $0.1 \mathrm{~N} \mathrm{NaCl}$ & $0.5 \mathrm{~N} \mathrm{NaCl}$ & $1.0 \mathrm{~N} \mathrm{NaCl}$ \\
\hline $2 \%$ & $6.626 \times 10^{-7}$ & $7.653 \times 10^{-7}$ & $1.006 \times 10^{-6}$ \\
$4 \%$ & $4.290 \times 10^{-7}$ & $5.626 \times 10^{-7}$ & $6.790 \times 10^{-7}$ \\
$6 \%$ & $1.597 \times 10^{-7}$ & $2.605 \times 10^{-7}$ & $3.643 \times 10^{-7}$ \\
& $1.564 \times 10^{-7}$ & $1.596 \times 10^{-7}$ & $2.067 \times 10^{-7}$ \\
\hline
\end{tabular}

Table 3. Corrosion rates of $\mathrm{Al} 6061$ matrix alloy and its TiN composites in various $\mathrm{NaCl}$ media.

\begin{tabular}{lccc}
\hline \multirow{2}{*}{$\begin{array}{l}\text { TiN content } \\
\text { in composites }\end{array}$} & \multicolumn{2}{c}{ Corrosion rate (milli inches per year) } \\
\cline { 2 - 4 } & $0.1 \mathrm{~N} \mathrm{NaCl}$ & $0.5 \mathrm{~N} \mathrm{NaCl}$ & $1 \cdot 0 \mathrm{~N} \mathrm{NaCl}$ \\
\hline $0 \%$ & $0 \cdot 2842$ & 0.3283 & 0.4300 \\
$2 \%$ & 0.1840 & $0 \cdot 2410$ & 0.2960 \\
$4 \%$ & 0.0841 & 0.1110 & 0.1560 \\
$6 \%$ & 0.0670 & 0.0684 & 0.0886 \\
\hline
\end{tabular}

in composites which could be attributed to its poor wettability as compared to $\mathrm{TiO}_{2}$ particles (Rhee 1970). The conducting TiN particulate possibly forms microgalvanic couple with Al 6061 matrix alloy and causes pitting corrosion. The observed decrease in corrosion rate in the case of composites is due to decoupling between TiN particles and Al 6061. It seems that after the initiation of corrosion, interfacial corrosion products may have decoupled the conducting ceramic TiN from Al 6061 matrix alloy, thus eliminating the galvanic effect between them (Srinivasan 2005).

Increase in the corrosion susceptibility of both Al 6061 matrix alloy and composites at higher concentrations of aggressive chloride ions is probably due to the breakdown of stable oxide film on Al 6061 matrix as a result of increased adsorption of chloride ions. This indicates the lowest corrosion tendency for the $\mathrm{TiN}(6 \mathrm{wt} \%)$-reinforced composites as compared to matrix alloy. The results show that the increase in $\mathrm{Cl}^{-}$ion concentrations yields more cathodic OCP values confirming enhanced adsorptivity of $\mathrm{Cl}^{-}$ions in both matrix alloy and its TiN composites. This corroborates the report by earlier researchers suggesting greater degree of penetration ability of chloride ions into the passive hydrated oxides of aluminium as well as reduction in the kinetics of oxide film repair.

Tafel polarization results show that TiN-reinforced composites have lower corrosion rate as compared to matrix alloy. Observations also show that both the $I_{\text {corr }}$ values and corrosion rate decrease with increase in content of TiN and increase with an increase in concentration of $\mathrm{NaCl}$ medium. This observation contradicts the composite theory of corrosion according to which reinforcement particles cause cracks and discontinuity on the surface of metal/alloy (Trowsdale et al 1996). It is observed that the interface between $\mathrm{Al}$ 6061 matrix and TiN reinforcement is stronger as reported 
(Sharma 2001) in the study of corrosive behaviour of $\mathrm{Al}$ 6061/albite composite. In the unreinforced $\mathrm{Al}$ alloy, the possible cathodic sites could be eutectic silicon and/or intermetallic precipitates; however, in the composites, cathodic sites may be reinforcements, second-phase precipitates or interfacial reaction products (Nunes and Ramanathan 1995).

The presence of a more conductive phase at the interface provides an easier path for the electron exchange necessary for oxygen reduction and drives the anodic reaction at a higher rate in MMCs than aluminium alloy. Improved corrosion resistance has been reported (Wlodarczyk-Fligier et al $2010)$ in $\mathrm{Al}$ composites reinforced up to $5 \% \mathrm{Ti}(\mathrm{C}, \mathrm{N})$ particulates when compared with the matrix alloy in $3 \% \mathrm{NaCl}$ medium. This corroborates the prediction that presence of a small amount of TiN reinforcement in composites fails to rupture the oxide layer of $\mathrm{Al}$. It is believed that the nature of the passive film formed on the TiN composites is sufficiently stable to reduce the corrosion rate after few min

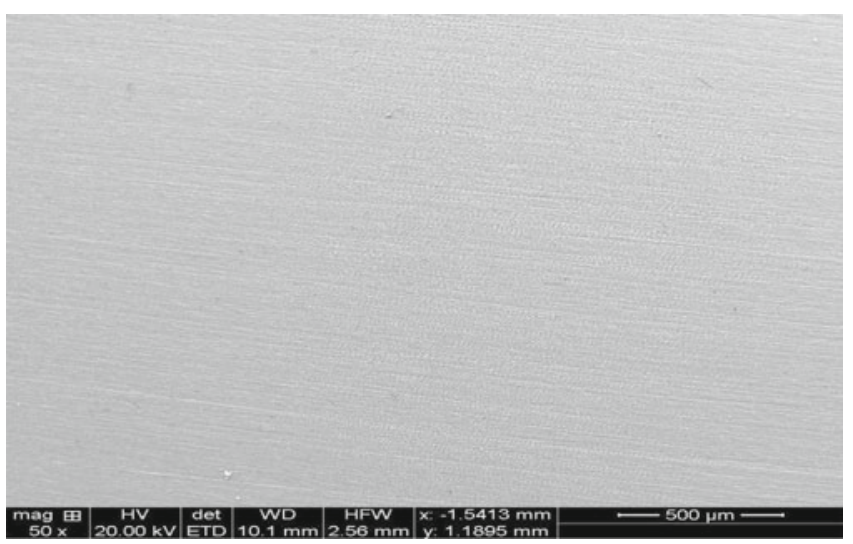

Figure 8. SEM micrograph of $\mathrm{Al} 6061$ matrix alloy. of immersion (Alaneme 2011). It has been reported that in the case of TiN-reinforced Al MMCs fabricated by powder metallurgical route (Ray et al 2002) that the presence of TiN-particles at grain boundaries played a significant role in its densification and improved mechanical as well as wear resistance properties. The improved corrosion resistance in TiN-reinforced Al 6061 composites compared to matrix alloy can be attributed to good interface bonding between the ceramic TiN and Al matrix alloy (Das 2004). TiN particle reinforced composites exhibit lesser surface irregularities which is due to refined microstructure as observed during the study of electrochemical behaviour of haematite particulates reinforced $\mathrm{Al}$ alloys (Jagadeesh et al 2005).

A probable explanation for the observed trend in pitting corrosion could be that the pitting is initiated at random sites of imperfections on the protective oxide layer of the matrix alloy, while in the composites, pits around the reinforcement particles coalesce to form a crevice. The active nature of the crevices would cathodically protect the remainder of the matrix and restrict pit formation and propagation (Garrard 1994). It is found that $E_{\mathrm{RP}}$ values increase in the noble direction with increasing TiN content in composites. This points to the fact that pit propagation in the composites is retarded more significantly than in the Al 6061 matrix alloy. The higher repassivation potential exhibited by the TiN-reinforced composites is attributable to the reduction in the pit dissolution kinetics by the oxides of metals. However, the repassivation potentials are more negative to the pitting potentials for each of the composites as well as the $\mathrm{Al} 6061$ matrix alloy indicating a tendency to undergo pitting. $\Delta E_{1}$ is the direct measure of pitting susceptibility and is used to assess the repassivation behaviour of propagating pits, the ease with which local active sites can be eliminated.

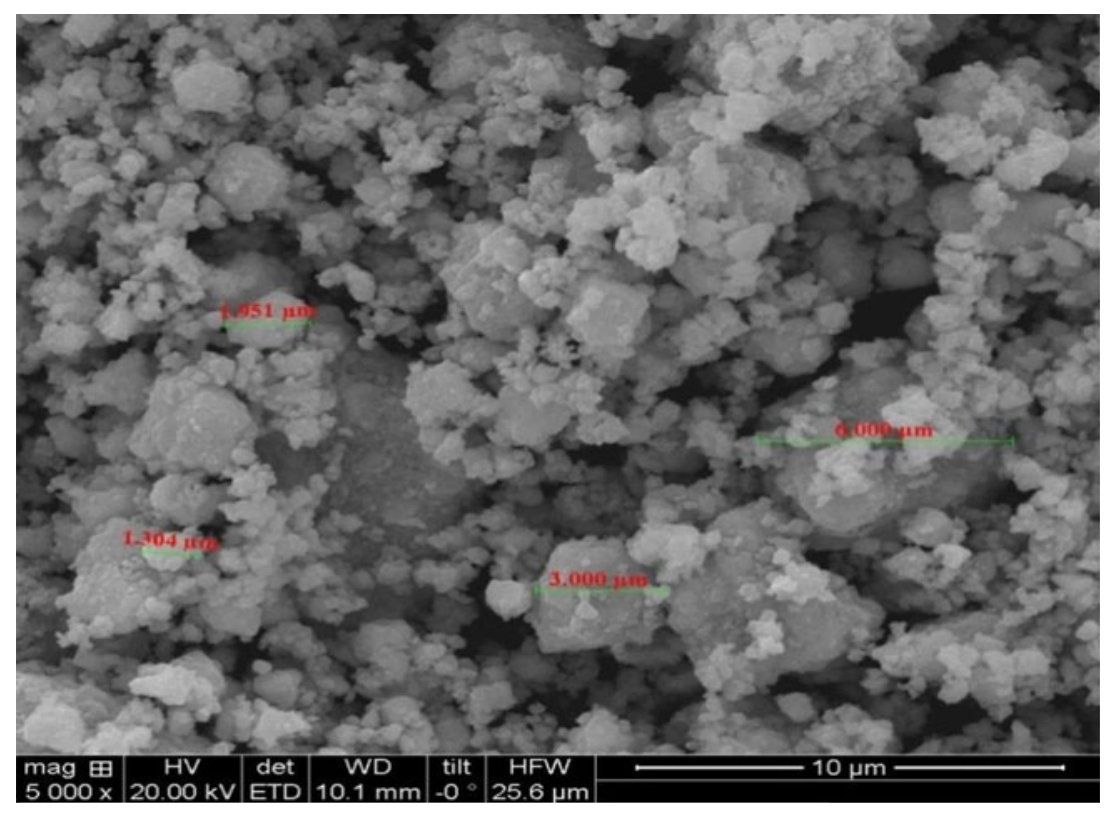

Figure 9. SEM micrograph of TiN particles. 


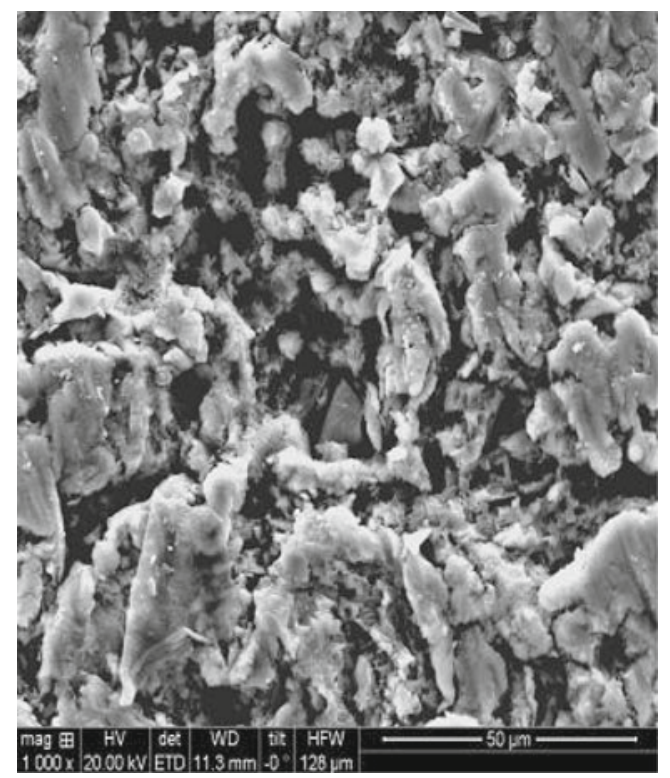

Figure 10. SEM micrograph of corroded Al 6061 matrix alloy.

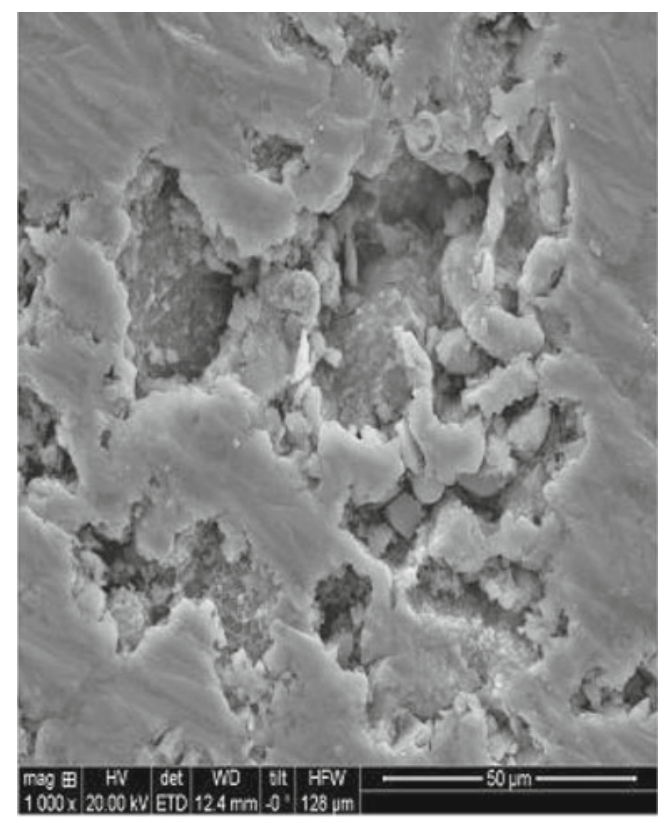

Figure 11. SEM micrograph of corroded Al 6061-TiN (2 wt\%) composite.

The pitting loop given by $\Delta E_{1}$ is observed to decrease from the matrix alloy to the composites and thus with increasing TiN content, a decreasing tendency to pitting in the TiN-reinforced composites is observed. However, the magnitude of change in pitting potential was found to be small $(59 \mathrm{mV})$ varying from $-0.7007 \mathrm{~V}$ in the matrix alloy to $-0.6597 \mathrm{~V}$ in the composite with highest content of TiN reinforcement (Murthy et al 2010).

Pitting corrosion resistance of the TiN particle reinforced composites has been observed to increase with increasing

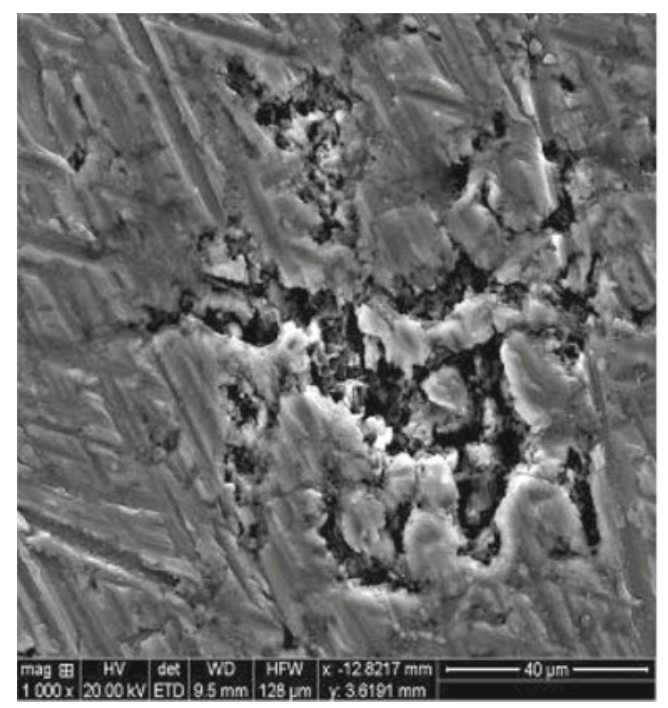

Figure 12. SEM micrograph of corroded Al 6061-TiN (4 wt $\%$ ) composite.

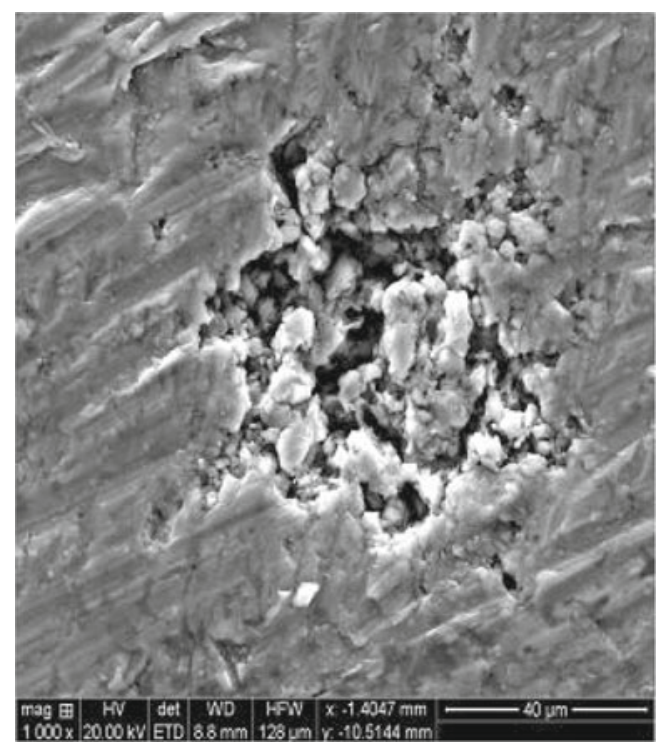

Figure 13. SEM micrograph of corroded $\mathrm{Al}$ 6061-TiN (6 wt $\%$ ) composite.

TiN content as reported by others (Kiourtsidis and Skolianos 2007). The $\Delta E_{2}$ value of $93.6 \mathrm{mV}$ in Al matrix alloy is found to increase to $159.5 \mathrm{mV}$ in $\mathrm{Al}-6 \mathrm{wt} \% \mathrm{TiN}$ composite. It can be seen that the addition of TiN to Al matrix significantly increases the passive range between the unreinforced matrix alloy and the reinforced composites.

\subsection{Scanning electron microscopy}

Scanning electron microscopy (SEM) images of the $\mathrm{Al} 6061$ matrix alloy before corrosion test and reinforcement TiN particles are shown in figures 8 and 9 , respectively. The 


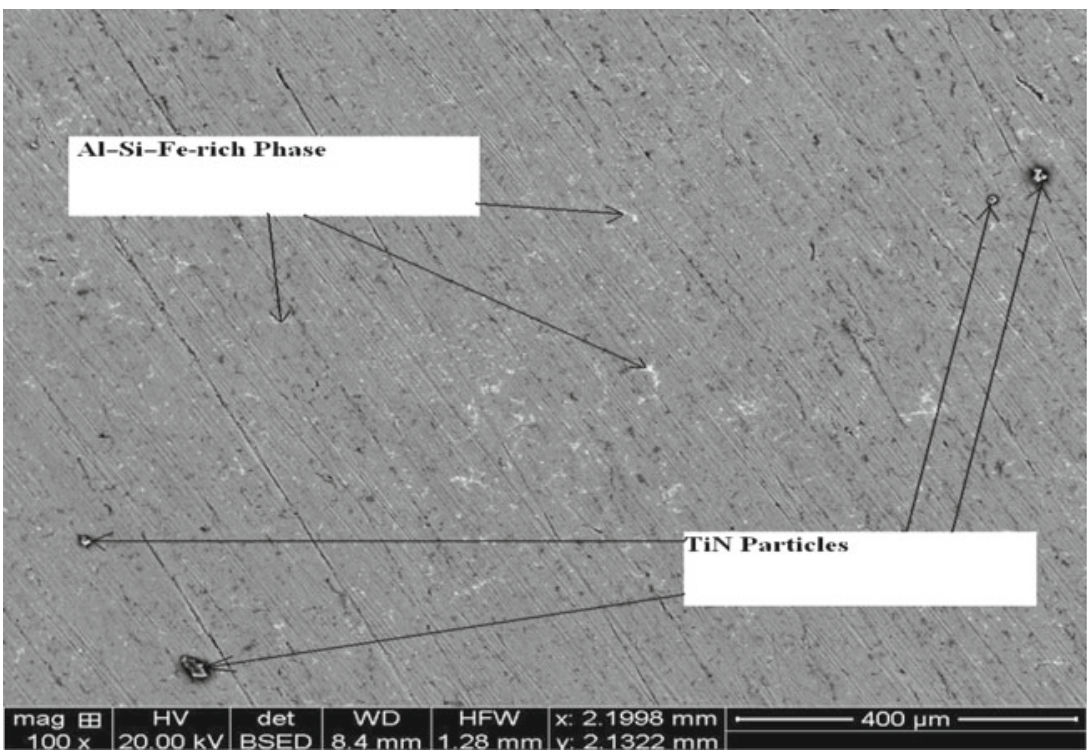

Figure 14. Back-scattered electron SEM of Al 6061-TiN (6 wt\%) composite showing regions of $\mathrm{Al}-\mathrm{Fe}-\mathrm{Si}$-rich phase and TiN particles.

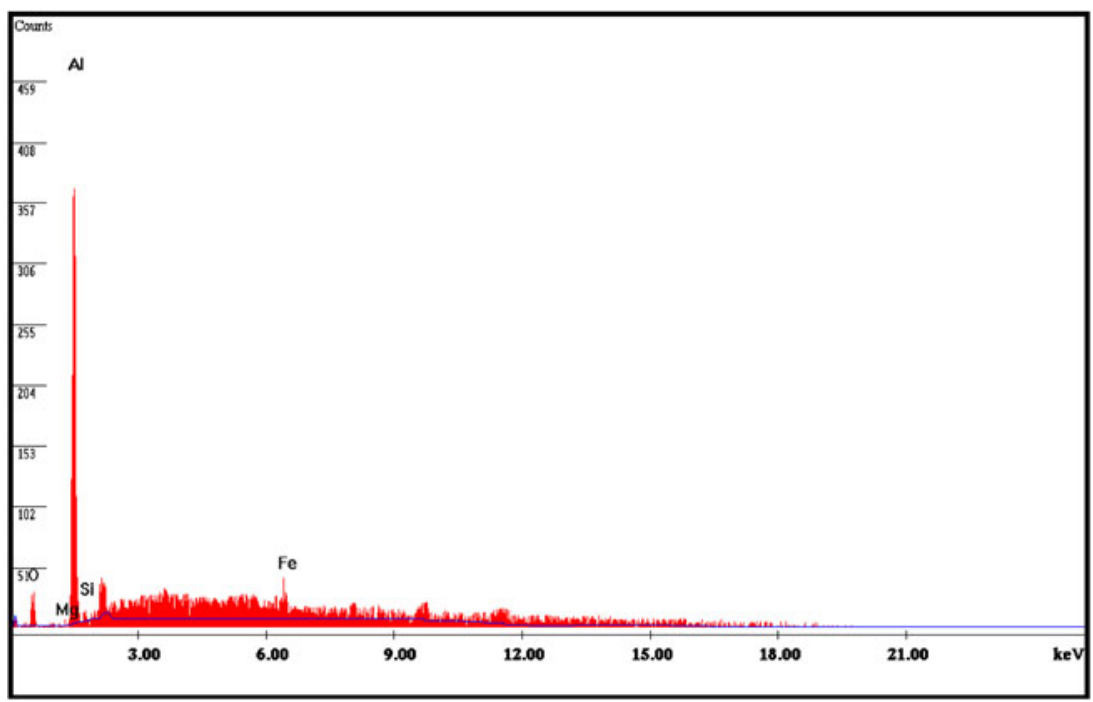

Figure 15. EDX spectrum of interface between TiN and Al 6061 matrix.

particle size of reinforcement TiN particulates is about $2-10 \mu \mathrm{m}$ as observed in the SEM image. SEM image of $\mathrm{Al}$ 6061 matrix alloy and its TiN (2, 4 and $6 \mathrm{wt} \%$ ) composites taken after polarization studies in decinormal chloride medium, after usual pretreatment, are presented in figures 10-13. A comparison of the SEM images of the samples before and after the polarization studies clearly indicates severe surface deterioration due to pitting corrosion in all the samples. Pitting susceptibility for aluminium alloys is mainly affected by the microstructural heterogeneity of these commercial alloys. The decrease in corrosion deterioration of composites can be attributed to matrix-reinforcement interfaces and formation of micro/sub-micro local cells at the metal surface.

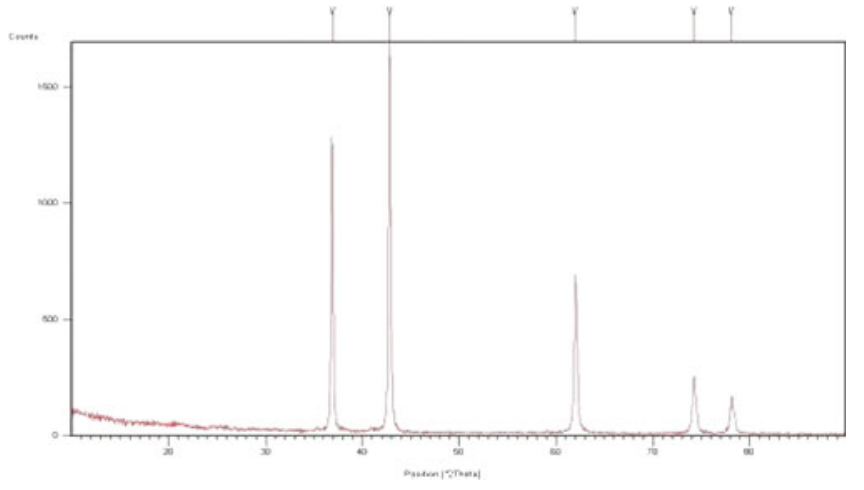

Figure 16. XRD pattern of TiN particulates. 
A rapid dissolution of aluminium within the pit tends to produce an excess of positive charge in this area. The migration of chloride ions towards the pit increases the concentration of $\mathrm{AlCl}_{3}$ in the pit. Since the solubility of oxygen is virtually zero in concentrated solution, no reduction of oxygen occurs within the pit. Cathodic oxygen reduction on surfaces adjacent to pits tends to suppress the corrosion thereby protecting the matrix metal adjacent to the pit (Ramachandra and Radhakrishna 2006).

\subsection{Energy dispersive $X$-ray analysis}

Energy dispersive X-ray (EDX) analysis spectra shows the presence of various elements in the TiN-reinforced $\mathrm{Al} 6061$

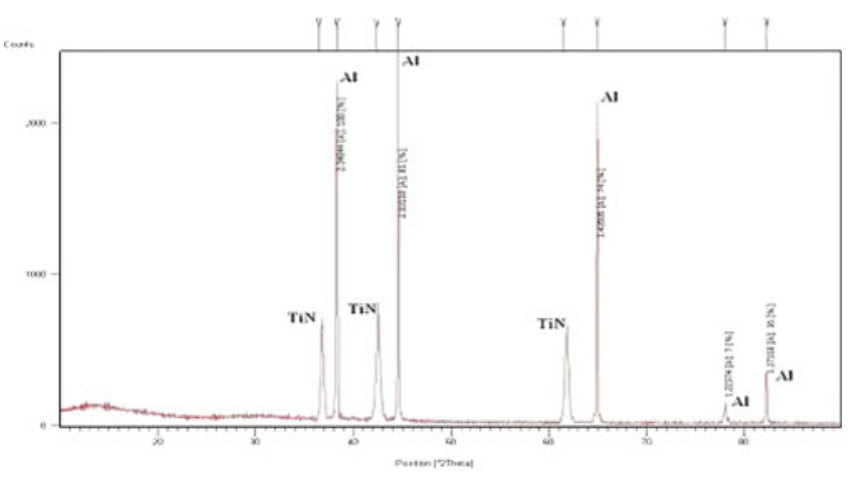

Figure 17. XRD pattern of TiN phase in $\mathrm{Al}$ 6061-TiN (6 wt $\%$ ) composite.

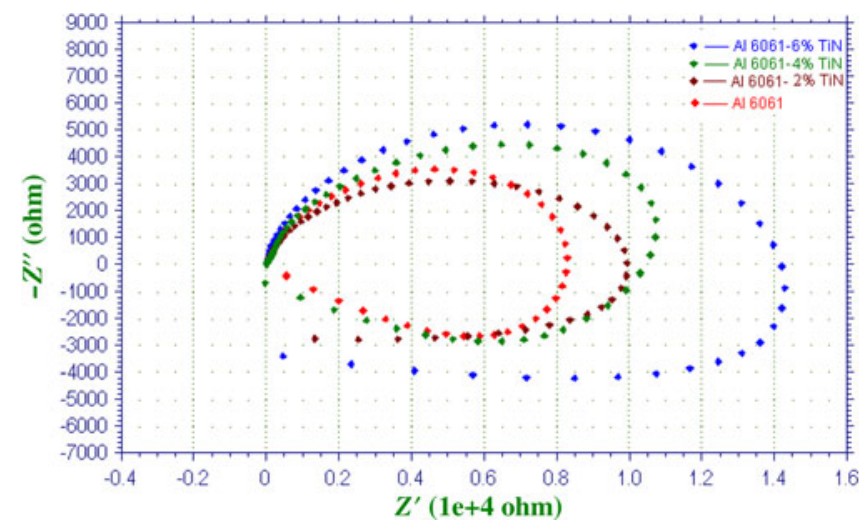

Figure 18. Nyquist plots of Al matrix alloy and its TiN composites in $0.5 \mathrm{~N} \mathrm{NaCl}$ medium. surface. The back-scattered SEM image of TiN (6wt\%)reinforced $\mathrm{Al} 6061$ sample is shown in figure 14. The presence of less intense peaks for the elements $\mathrm{Ti}$ and $\mathrm{N}$ in the EDX spectrum of TiN (6 wt\%)-reinforced Al 6061 composite confirms the incorporation of TiN particles into Al matrix, but only to a small extent as it exhibits low wettability.

Even though galvanic coupling is assumed to be established between conductive $\mathrm{TiN}$ and $\mathrm{Al}$ matrix alloy, the extent of corrosion is insignificant (Adler et al 2008) even at $6 \mathrm{wt} \%$ of TiN particles in composites. It is observed that the matrix alloy and composites contain $\mathrm{Al}-\mathrm{Fe}-\mathrm{Si}$-rich and $\mathrm{Mg}_{2} \mathrm{Si}$ intermetallic phases.

The elements in these intermetallic phases undergo oxidation to yield their respective oxides such as $\mathrm{SiO}_{2}, \mathrm{FeO}$ and $\mathrm{MgO}$, which reduce the corrosion rate in composites by decreasing the microgalvanic coupling between conducting intermetallic phases and matrix alloy. The presence of $\mathrm{SiO}_{2}$, $\mathrm{FeO}$ and $\mathrm{MgO}$ at the interface between TiN and $\mathrm{Al} 6061$ is confirmed by EDX spectrum which showed intense peaks for $\mathrm{Si}, \mathrm{Fe}, \mathrm{Mg}$ and $\mathrm{O}$ as shown in figure 15 . Corrosion resistance is more pronounced in TiN-reinforced composites as they contain higher amount of intermetallic phases due to the possible increased reactivity between the reinforcement particle and other alloying elements.

\section{$3.4 \quad X$-ray diffraction studies}

X-ray diffraction (XRD) pattern of the composite ( $6 \mathrm{wt} \%$ $\mathrm{TiO}_{2}$-reinforced) and that of $\mathrm{TiN}$ particulates is given in figures 16 and 17. XRD spectra of the composite clearly shows major $2 \theta$ peaks of $\operatorname{TiN}\left(36.87^{\circ}, 42.78^{\circ}\right.$ and $\left.61.98^{\circ}\right)$ in the TiN (6\%)-reinforced $\mathrm{Al} 6061$ composite indicating the incorporation of reinforcement particulates in the matrix alloy.

\subsection{EIS studies}

EIS study of the matrix alloy and its composites is carried out at OCP in order to assess the contribution of oxide film on $\mathrm{Al}$ to the corrosion resistance of the composites. Nyquist plots of the $\mathrm{Al} 6061$ matrix alloy and its TiN composites in $0.5 \mathrm{~N} \mathrm{NaCl}$ medium is shown in figure 18. It can be observed from the Nyquist plots that radius of the capacitive loops above the real axis increased with increase in TiN content for composites.

Electrochemical parameters obtained in EIS studies of $\mathrm{Al}$ 6061 matrix alloy and its TiN composites are given in table 4 .

Table 4. Electrochemical parameters for Al 6061 matrix alloy and its TiN composites obtained from EIS studies.

\begin{tabular}{lccc}
\hline $\begin{array}{l}\text { TiN content } \\
\text { in composites }\end{array}$ & $\begin{array}{c}R_{\mathrm{S}} \\
(\mathrm{ohm})\end{array}$ & $\begin{array}{c}R_{\mathrm{p}} \\
(\mathrm{ohm})\end{array}$ & $\begin{array}{c}\mathrm{CPE} \\
(\mathrm{F})\end{array}$ \\
\hline $0 \%$ & 2.843 & 13208 & $9.42 \times 10^{-6}$ \\
$2 \%$ & 2.981 & 15680 & $1.59 \times 10^{-6}$ \\
$4 \%$ & 3.873 & 23768 & $7.83 \times 10^{-7}$ \\
$6 \%$ & 4.432 & 29831 & $5.94 \times 10^{-7}$ \\
\hline
\end{tabular}


Based on the analysis of the impedance spectra, an equivalent circuit model $R[Q R[L R]]$ was proposed for both the matrix alloy (figure 19) and composites (figure 20), simulating their electrochemical behaviour.

It can be found that the impedance spectra of all the samples are dominated by capacitance of the oxide film, but the diameters of the capacitance arcs increase with increase in TiN content, which means that the resistance of the surface oxide film on the composites increases with increase in TiN reinforcement.

This can be attributed to the fact that the hydroxide formed by the oxides of $\mathrm{Si}, \mathrm{Mg}$ and $\mathrm{Al}$ plays an inhibitive role around conducting TiN and intermetallic phases. The equivalent circuit consists of a constant phase element (CPE), $Q$, in parallel with the parallel resistors, $R_{\mathrm{t}}$ (charge transfer resistance) and $R_{\mathrm{L}}$ (inductance resistance) and the latter is in series with the inductor $L$. In this case, the polarization resistance can be calculated using the formula as given below:

$$
R_{\mathrm{p}}=\frac{R_{\mathrm{L}} \times R_{\mathrm{t}}}{R_{\mathrm{L}}+R_{\mathrm{t}}} .
$$

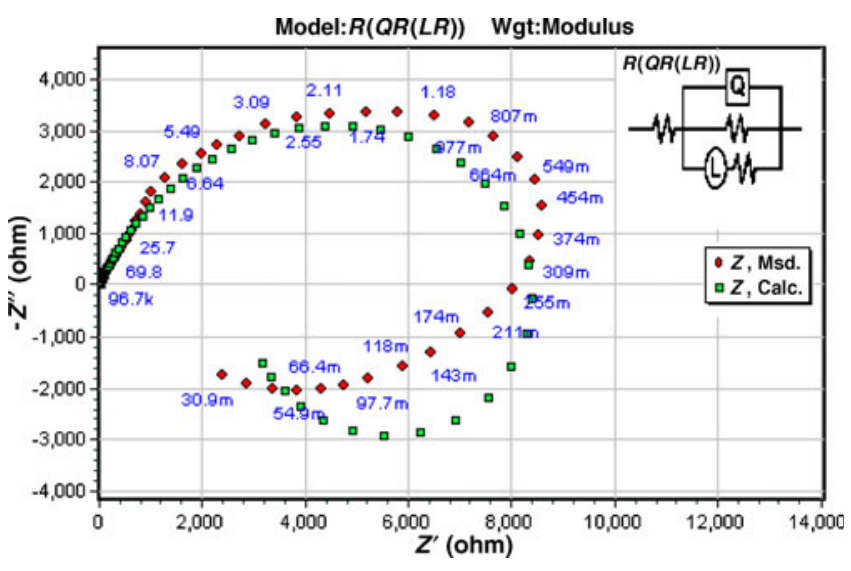

Figure 19. Equivalent circuit model used to fit the experimental data of $\mathrm{Al} 6061$ matrix alloy in $0.5 \mathrm{~N} \mathrm{NaCl}$ medium.

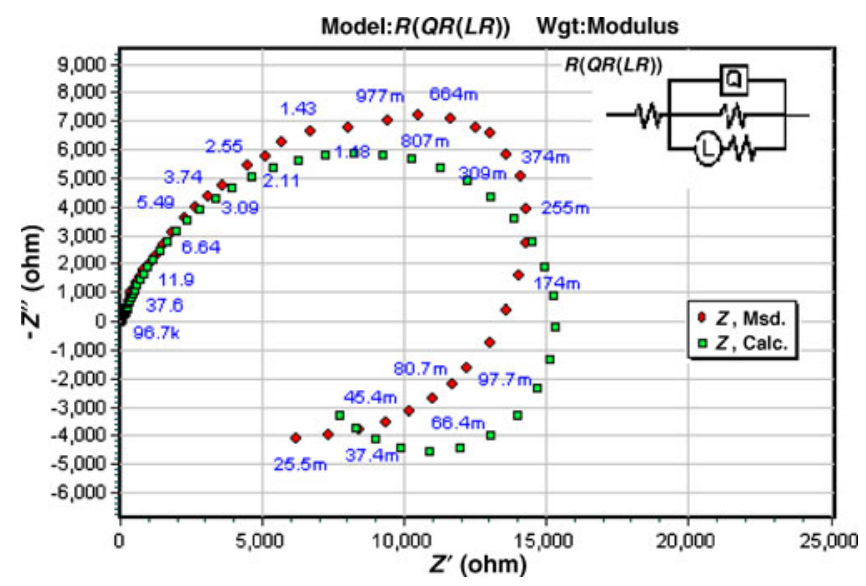

Figure 20. Equivalent circuit model used to fit the experimental data of $\mathrm{Al} 6061-\mathrm{TiN}(6 \mathrm{wt} \%$ ) composite in $0.5 \mathrm{~N} \mathrm{NaCl}$ medium.
Impedance spectroscopic studies show decreasing trend of polarization resistance, $R_{\mathrm{P}}$, on increase of $\mathrm{TiN}$ reinforcement.

The measured value of polarization resistance, $R_{\mathrm{p}}$, increases while the CPE value decreases with increase in TiN content. This shows that the corrosion rate decreases with increase in the content of TiN reinforcement. It is also observed that the $R_{\mathrm{p}}$ value increases with increase in TiN content confirming improved corrosion resistance in composites. These results complement polarization tests and are similar to the $\mathrm{TiO}_{2}$ composites system.

\section{Conclusions}

The corrosion behaviour of unreinforced Al 6061 matrix alloy and its composites reinforced with $\mathrm{TiN}(2,4$ and $6 \mathrm{wt} \%$ ) were studied in $0.1 \mathrm{~N}, 0.5 \mathrm{~N}$ and $1 \mathrm{~N} \mathrm{NaCl}$ media. Corrosion rates of the matrix alloy and the composites from the polarization curves, show a decrease with increase in the content of TiN reinforcement. Increased corrosion resistance in composites is believed to be due to reinforcement particulates modifying the microstructure of matrix and also acting as physical barrier to the initiation and development of pitting corrosion. Increase in the corrosion susceptibility of both Al 6061 matrix alloy and the composites at higher concentrations of aggressive chloride ions is probably due to the breakdown of stable oxide film on Al 6061 matrix as a result of increased adsorption of chloride ions. XRD and EDX analysis of all the composites confirm positive inclusion of the reinforcement particulates in the matrix alloy and also the presence of intermetallic phases such as Al$\mathrm{Fe}-\mathrm{Si}$-rich and $\mathrm{Mg}_{2} \mathrm{Si}$ formed at matrix-reinforcement interface. SEM pictures reveal severe deterioration of the surface of both matrix alloy and its composites of all the reinforcements. The measured value of polarization resistance, $R_{\mathrm{p}}$, increases while the CPE value decreases with increase in content of reinforcement in all the cases.

\section{Acknowledgements}

The authors are grateful to the Principal Dr M K Venkatesha, the Director Dr H N Shivashankar and the management of RNS Institute of Technology, Bangalore and the Principal and Management of Dr Ambedkar Institute of Technology, for their support and encouragement towards our research.

\section{References}

Adler R P I, Daniel J S, George H and Hihara L H 2008 Characterization of corrosion on outdoor-exposed aluminum metal-matrix composites as a function of reinforcement specie and volume fraction (USA: University of Hawaii)

Agarwal B D and Broutman L J 1980 Analysis and performance of fiber composites (New York: John Wiley \& Sons) p. 3

Alaneme K 2011 Leonardo J. Sci. 1855

Berghezan A 1966 Nucleus 816 
Chawla N and Chawla K K 2006 Metal matrix composites (New York, USA: Springer Science + Business Media Inc)

Chawla N and Chen Y 2001 Adv. Eng. Mater. 3357

Clyne T W and Withers P J 2001 Encyclopaedia of materials: science and technology composites MMC, CMC and PMC (ed.) A Mortensen (Amsterdam, The Netherlands: Elsevier)

Das S 2004 Trans. Indian Inst. Met. 57325

Froyen L and Verlinden B 1994 Aluminium matrix composite materials (Belgium: University of Leuven)

Garrard W N C 1994 Corros. Sci. 36837

Griffiths A J and Turnbull A 1994 Corros. Sci. 3623

Jagadeesh H N, Ramaa M S, Suresh K V and Niranjan H B 2005 Electrochemical behaviour of plastically deformed Al 2024 haematite composites, National conference on mechanical engineering, NATCON ME-2005 (Belgaum: Visvesvaraya Technological University)

Johansen H G and Hydro Aluminium Structures 2010 TALAT lecture 2203: structural materials fabrication.

Kainer K U 2006 Custom made materials for automotive and aerospace engineering (Weinheim: Wiley-VCH Verlag $\mathrm{GmbH} \&$ $\mathrm{Co}, \mathrm{KGaA})$

Kelly A 1967 Sci. Am. B217 161

Kiourtsidis G E and Skolianos S M 2007 Corros. Sci. 492711

Murthy H C A, Sanaulla P F and Raju V B 2010 Electrochim. Acta 28309
Nair S V, Tien J K and Bates R C 1985 Int. Met. Rev. 30275

Nunes P C R and Ramanathan L V 1995 Corros. Sci. 51 610

Paciej R C and Agarwala V S 1986 Corrosion 42718

Pfeifer W H 1977 Corrosion of graphite/aluminium, hybrid and select metal matrix composites: A state of the art review (ed.) W J Renton (New York: American Institute of Aeronautics and Astronautics) p. 231

Pohlman S L 1978 Corrosion 35156

Ramachandra M and Radhakrishna K 2006 Mater. Sci. Poland 24 333

Ray A K, Venkateshwarlu K, Chaudhary S K, Das S K, Kumar B R and Pathak L C 2002 Mater. Sci. Eng. A338 160

Rhee S K 1970 Am. Ceram. Soc. 53386

Sharma S C 2001 Corros. Sci. 431877

Srinivasan R 2005 Corrosion studies between ceramics and 6061 Al-T6 interface, MS Thesis, University of Hawaii, USA

Trowsdale A J, Noble B, Harris S J, Gibbins I S R, Thompson G E and Wood G C 1996 Corros. Sci. 38177

Trumper R L 1987 Met. Mater. 3662

Trzaskoma P P, McCafferty E M and Crowe C R 1983 J. Electrochem. Soc. 1301804

Wlodarczyk-Fligier A, Adamiak M and Dobrzanski L A 2010 J. Achiev. Mater. Manuf. Eng. 42120 